\title{
Assessment of diesel particulate matter exposure among underground mine workers
}

\author{
D. Bertolatti, K. Rumchev \& B. Mullins \\ Curtin Health Innovation Research Institute and \\ The School of Public Health, Curtin University, Australia
}

\begin{abstract}
Diesel motor emissions are a major source of ultrafine particles as research shows that the particulate fraction of diesel exhaust consists mainly of very small particles, which rapidly agglomerate to form clumps of particles with $<1 \mu \mathrm{m}$ aerodynamic size. Substantial scientific evidence supports that inhalation of emissions from diesel exhaust particulates is associated with a range of adverse health effects. Measurements have shown that underground miners can be exposed to over 100 times the typical environmental concentrations of diesel particulate matter (DPM) and over 10 times the concentration measured in other work environments where diesel engines are common. This paper reports personal and environmental exposures to DPM in an underground mine in Western Australia. The findings demonstrated that the DPM concentration exceeded the provisional 8-hour time weighted average exposure standard of $0.1 \mathrm{mg} / \mathrm{m}^{3}$ for most of the assessed locations. The elemental analysis indicated high concentrations of silica and iron in DPM which could be potentially associated with some adverse health effects including respiratory illnesses and irritating effects. Thermal comfort underground was also assessed and the results showed non compliance with the standards of the American Society of Heating, Refrigerating and Air-Conditioning Engineers (ASHRAE).

Keywords: diesel exhaust, diesel particulate matter, fine and ultrafine particles.
\end{abstract}

\section{Introduction}

Exhaust particles emitted from in-use diesel vehicles in underground mining operations are a major source of ultrafine carbonaceous particles, which have the potential to produce adverse health effects. The particulate fraction of diesel 
exhaust consists of fine particles (typically aerodynamic diameter $<2.5 \mu \mathrm{m}$ ) including a high number of ultrafine particles (diameter $<0.1 \mu \mathrm{m}$ ) that include reactive organic and transition metal components [1].

Particles in the ultrafine size range have attracted significant scientific and medical attention since research shows that for equivalent masses of inhaled particles, ultrafine particles provide a greater surface area for adsorption of potentially toxic substances and metal agents. Further to this, ultrafine particles have also a higher deposition probability particularly in small airways and the alveolar region of the lungs than coarse particles. With regards to health outcome, the small particle size of diesel particulate matter (DPM) is considered a significant health issue as such particles can penetrate deep in the lungs [2-4]. In 1988, the National Institute of Occupational Safety and Health (NIOSH) [5] recommended that diesel exhaust be regarded as a "potential occupational carcinogen". Similarly, in 1989, the International Agency for Research on cancer declared that "diesel engine exhaust is probably carcinogenic to human" [6]. Measurements have shown that underground miners can be exposed to over 100 times the typical environmental concentrations of diesel particulate matter (DPM) and over 10 times the concentration measured in other work environments where diesel engines are common [7-9].

Based on the current research evidence, the US National Research Council has concluded that the NIOSH Research Mining Program, related to exposure of DPM and related health effects, is considered as a high priority with a rating of four on a five-point scale [10]. Furthermore, evidence is increasingly being accumulated which suggests that nanoparticles (such as diesel soot which typically has a primary particle size $<50 \mathrm{~nm}$ ) affect health as a function of surface area rather than mass [11].

The study assessed personal and environmental exposures of diesel particulate matter (DPM) in an underground mine using various sampling system that included, low pressure cascade impactor (Nano-MOUDI-II) and scanning mobility particle size (SMPS) measurements. This research forms part of a wider study with the major milestone to reduce exposure levels of diesel particulate matter (DPM) and improve the air quality underground.

\section{Methods and materials}

The study was undertaken in a large underground mine in north-western Australia. The experimental method was designed to: (a) accurately measure DPM in real-time at representative locations, (b) collect size-fractioned DPM and other particulate for gravimetric measurement and analysis, (c) determine worker exposure levels.

\subsection{Apparatus}

The experimental apparatus consisted of, a NanoMOUDI 125B multi-stage low pressure impactor (MSP, Shoreview, MN, USA), a Scanning Mobility Particle Sizer (SMPS) consisting of a TSI 3081 Differential Mobility Analyzer (DMA) 
and TSI 3775 Condensation Particle Counter (CPC) (TSI, Shoreview, MN, USA), a TSI DustTrak 8533 DRX, with a TSI P-Trak, TSI Velocicalc-Plus used to obtain air velocity, temperature and humidity measurements. Four SKC air pumps and filters were utilized for personal monitoring of mine-worker exposures. NIOSH method 5040 (Elemental Carbon) was applied to quantify elemental carbon (EC) via thermal-optical analyzer. Samples collected using the NanoMOUDI were analysed for elemental composition of by Scanning Electron Microscopy (SEM) Analysis and performed by the ChemCentre of WA. Analysis of organic species and PAHs was also undertaken.

\subsubsection{Methods}

Measurement sites were established at 4 representative locations within the mine:

Site 1 - The main fresh air inlet (baseline measurement) for the mine.

Site 2 - A dead-end passage at the base of the tunnel network with no airflow.

Site 3 - An active area of the mine where material extraction was actively occurring.

Site 4 - A site near the main air outlet from the mine.

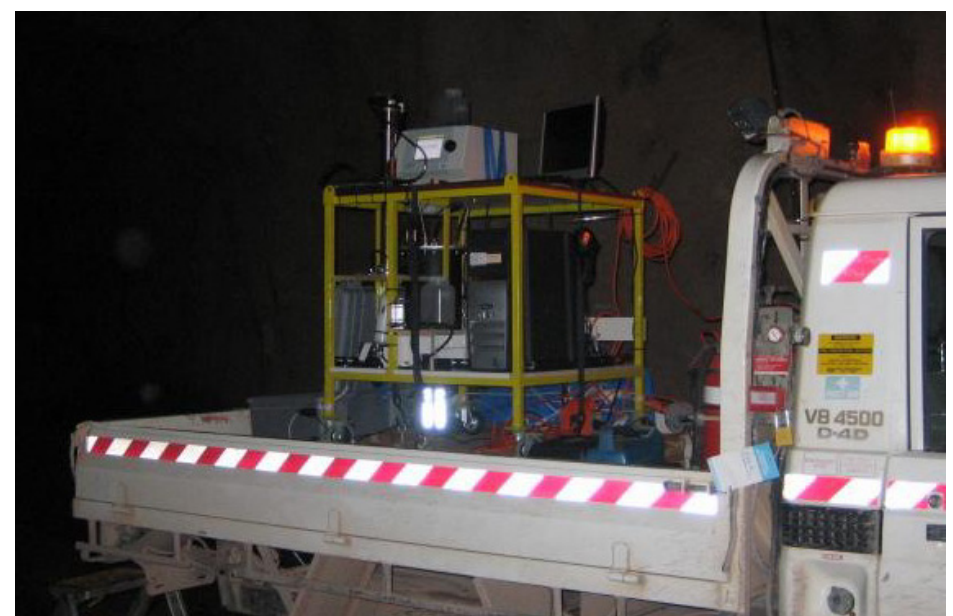

Figure 1: $\quad$ Sampling equipment located on mine vehicle, in location at site 1.

Samples were taken at a height equivalent to the roof level of the vehicle. Sampling commenced at least 30 minutes after the vehicle was placed into position. The NanoMOUDI is not visible in image. Measurements were also taken above ground to compare with the fresh air inlet values.

At each site 1-4, measurements were taken continuously for a period of 6 14 hours. During each measurement, the NanoMOUDI, DustTrak and P-Trak were set to measure continuously. The SMPS was set to perform repeated scans between $15 \mathrm{~nm}$ and $950 \mathrm{~nm}$ at intervals of approximately 15 minutes. At the end of each measurement the equipment was taken to a clean laboratory on the surface where samples/filters could be removed and weighed, and data 
downloaded, etc. At the start of each working shift, three workers were fitted with personal samplers, selected based on their proximity to the sampling location. The samplers were collected after 8 hours and the filters removed for analysis. For the time period where samples were being collected, information on vehicle movements and vehicle locations were obtained from the mine telemetry/logistics system. This made it possible to track vehicle movement past the sampling location.

\section{Results and discussion}

Table 1 shows the airflow, temperature and humidity values recorded at each sampling location.

Table 1: Environmental conditions at each sampling location.

\begin{tabular}{|c|c|c|c|c|}
\hline Site & Location & $\begin{array}{c}\text { Mean Temp } \\
\left({ }^{0} \mathrm{C}\right)\end{array}$ & $\begin{array}{c}\text { Mean R.H. } \\
(\%)\end{array}$ & $\begin{array}{c}\text { Mean Air Vel. } \\
(\mathrm{m} / \mathrm{sec})\end{array}$ \\
\hline 1 & Fresh air inlet & 11.7 & $75 \%$ & 2.01 \\
\hline 2 & Dead end tunnel & 36.5 & $98 \%$ & 0.17 \\
\hline 3 & Active extraction & 30.2 & $83 \%$ & 0.18 \\
\hline 4 & Near air exhaust & 31.1 & $90 \%$ & 0.57 \\
\hline \multicolumn{2}{|c|}{$\begin{array}{c}\text { Recommended range } \\
\text { (ASHRAE 2004) }\end{array}$} & $21-26$ & $30-70$ & $0.1-0.2$ \\
\hline
\end{tabular}

It will be noted that humidity levels are extremely high. This was due to a combination of evaporative cooling of the mine intake air, water sprays for dust suppression within the mine, and also artesian water which enters the mine and evaporates. It will be noted that relative humidity and temperature in the dead end tunnel were both exceptionally high. During the time of the measurement campaign, the mine was operating at approximately $30 \%$ of its typical operating capacity, due to the global financial crisis reducing demand/value of the mine production. Therefore particulate levels measured during this campaign could be expected to be near the lower levels of typical worker exposure.

\subsection{Personal monitoring}

Table 2 shows the results for personal monitoring, for sites 1, 3 and 4, averaged over 8 hours. Site 2 did not have any workers in the area while sampling was conducted, hence no data was possible.

The samplers were fitted to workers at the start of each shift. Workers would typically spend the first hour or more of each shift above ground, and then may come above ground for lunch and other breaks (though this is not enforced and underground refuge areas are often used for breaks). The vehicle operators have air conditioned vehicle cabins; however some choose to operate their vehicles with the windows open. The drill vehicles are the only electric vehicles in the 
Table 2: $\quad$ Personal exposure to DPM (measured as elemental carbon).

\begin{tabular}{|c|c|c|}
\hline Site & Worker & $\begin{array}{c}\text { Elemental Carbon } \\
\left(\mathrm{mg} / \mathrm{m}^{3}\right)\end{array}$ \\
\hline 1 & Loader (“Bogger") driver & 0.06 \\
& Truck driver & 0.03 \\
& Fixed position & $<0.002$ \\
\hline 3 & Assistant driller & 0.03 \\
& Drill vehicle driver & 0.03 \\
& Fixed position & 0.05 \\
\hline 4 & Explosives technician & 0.078 \\
& Service/breakdown mechanic & 0.11 \\
& Fixed position & 0.085 \\
\hline
\end{tabular}

mine, which accounts for the low exposure of the driller and assistant driller. The underground service/maintenance mechanics and the explosives technicians are the only workers who are usually required to spend extended periods out of a vehicle in the mine, which accounts for the elevated readings for these workers. However these latter two types of workers drive between tasks in air conditioned $4 \times 4$ vehicles.

\subsubsection{Stationary sampling results}

Table 3 below shows the PM 1 levels measured by NanoMOUDI. This was selected as it is the size range which includes almost all DPM. EC values have also been determined from the total gravimetric measurements of PM 1. The aerosol in the mine was found to be bimodal. There existed a sub-micron peak, which consisted almost entirely ( $>99 \%$ by mass) of DPM, and a super-micron peak (at approximately 2-5 microns), which consisted of crustal materials from the mine, combined with high levels of silica (likely from the spray-concrete used to secure the ceiling and walls of the mine.

Table 3: $\quad$ PM1 and DPM levels as measured by NanoMOUDI.

\begin{tabular}{|c|c|c|c|}
\hline Site & $\begin{array}{c}\text { Sampling Time } \\
\text { (hours: mins) }\end{array}$ & $\begin{array}{c}\text { Average PM1 conc. } \\
\left(\mathrm{mg} / \mathrm{m}^{3}\right)\end{array}$ & $\begin{array}{c}\mathrm{EC} \\
\left(\mathrm{mg} / \mathrm{m}^{3}\right)\end{array}$ \\
\hline 1 & $6: 00$ & $0.08 \mathrm{mg} / \mathrm{m}^{3 *}$ & $0.03 \mathrm{mg} / \mathrm{m}^{3 *}$ \\
\hline 2 & $8: 50$ & $0.11 \mathrm{mg} / \mathrm{m}^{3}$ & $0.09 \mathrm{mg} / \mathrm{m}^{3}$ \\
\hline 3 & $6: 55$ & $0.16 \mathrm{mg} / \mathrm{m}^{3}$ & $0.13 \mathrm{mg} / \mathrm{m}^{3}$ \\
\hline 4 & $14: 10$ & $0.12 \mathrm{mg} / \mathrm{m}^{3}$ & $0.10 \mathrm{mg} / \mathrm{m}^{3}$ \\
\hline
\end{tabular}

*A high level of elemental carbon was present in the intake air due to wildfires in the vicinity of the mine preceding the sampling period. 
It can be observed that a nontrivial proportion of the (clean) intake air was elemental carbon. This was believed to largely be due to recent wildfires, rather than vehicle movement on the surface. It will be noted that the average levels are very high, despite the fact that the mine was operating at approximately $30 \%$ of normal production levels.

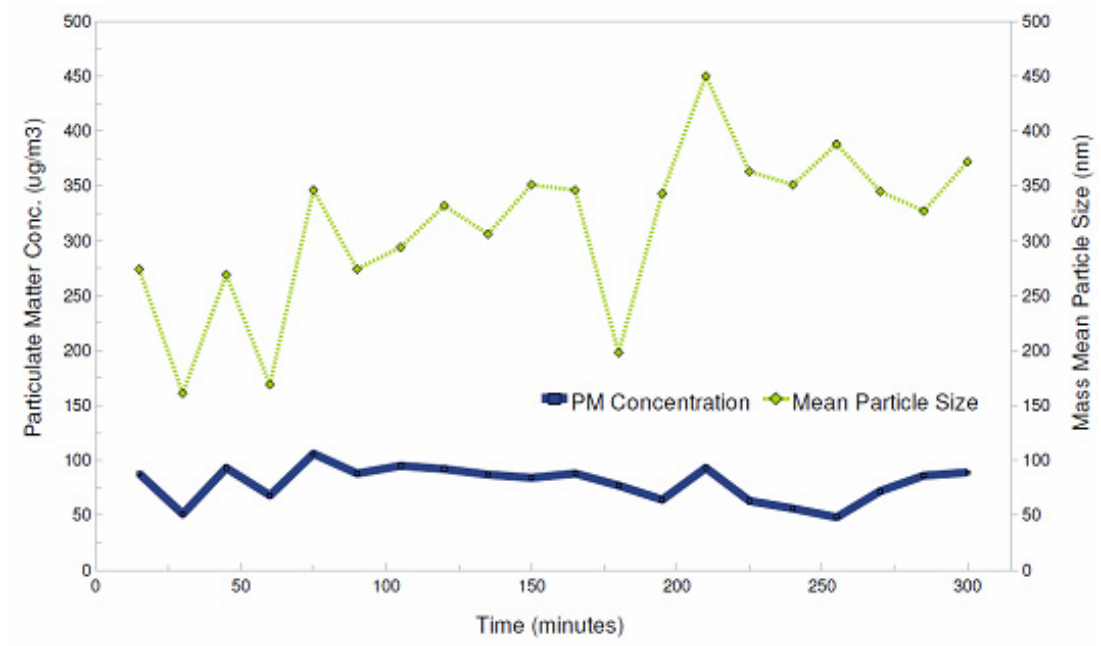

(a)

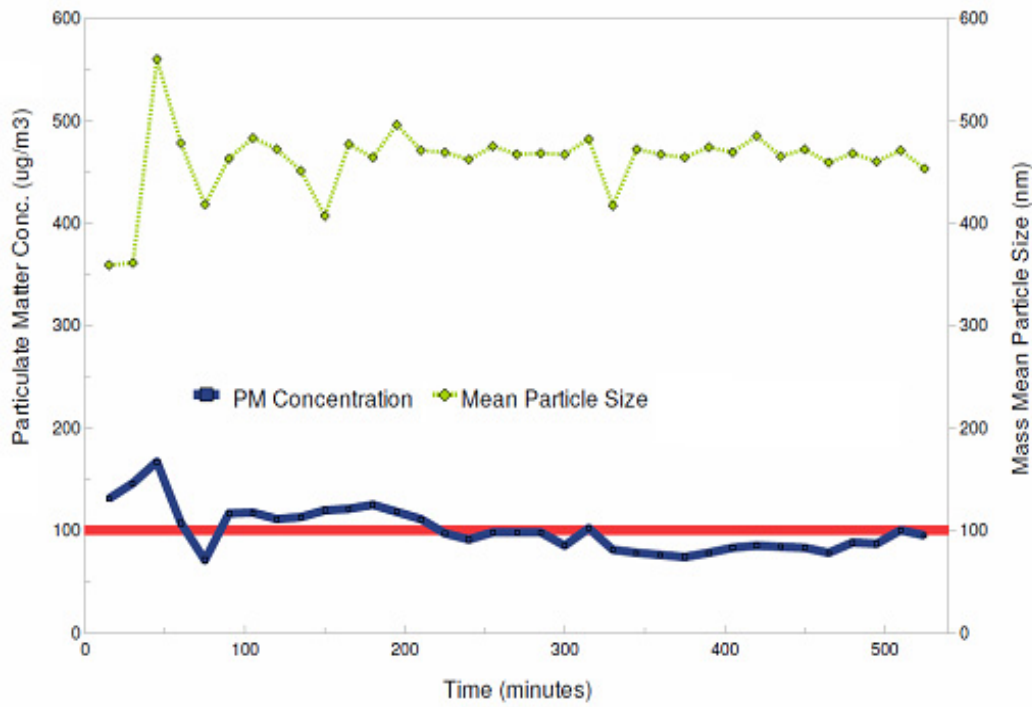

(b)

Figure 2: $\quad$ Time dependent mass and size of PM 1 (DPM) as measured using the SMPS. (a) Site 1, (b) Site 2, (c) Site 3. The red line denotes the time weighted DPM exposure limit of $0.1 \mathrm{mg} / \mathrm{m}^{3}$. 


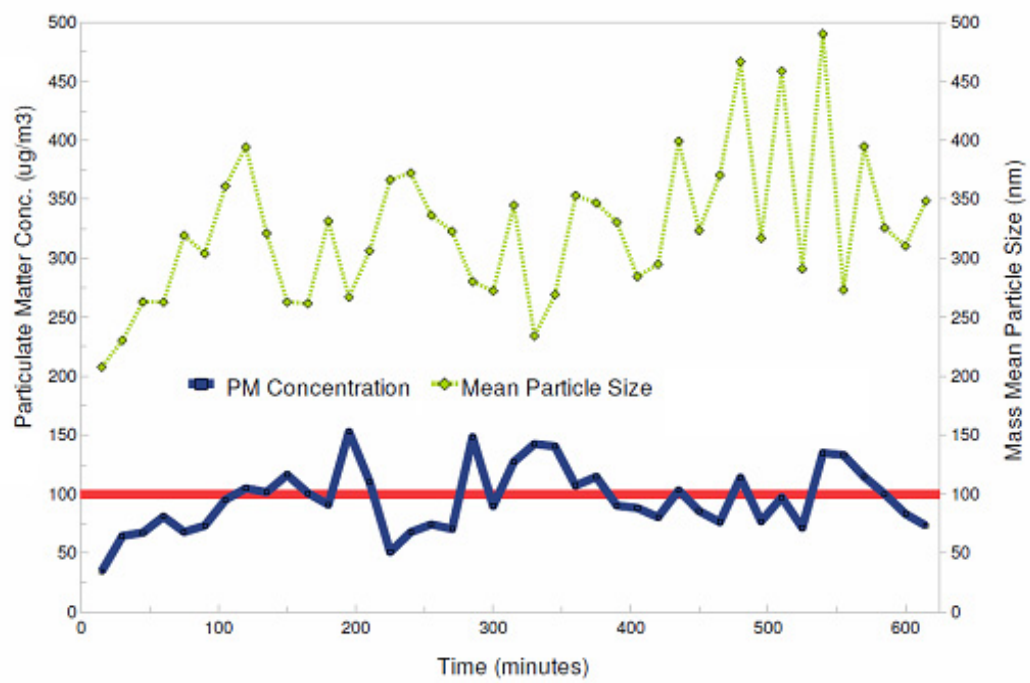

(c)

Figure 2: Continued.

Figure 2(a-c) shows the temporal evolution of PM 1 at sites $1-3$. It can be observed that at sites 1 and 2 the values were relatively stable, as site 1 has a constant airflow of air which has passed through a filtration and conditioning system, and Site 2 has a low airflow and a very low air exchange rate. Site 3 however, had a mine vehicle (loader/bogger) working in close proximity to the sampling apparatus. It will be observed than an increase in particle mass often corresponds to a decrease in particle size. The mine telemetry data showed that these samples coincided with the loader passing by the sampling location, resulting in a high concentration of smaller particles which had just been emitted from the exhaust, and had not had sufficient time to dissipate or agglomerate.

\subsubsection{Elemental composition of PM}

An elemental analysis of the PM collected by the NanoMOUDI was also performed. The total particulate matter values for all size classes have been combined. Over $50 \%$ of the inorganic contaminants were found in the PM 2.5 fraction.

It can be observed that high levels of Silica and Iron were present, with levels of vanadium also elevated. The Silica is likely due to the concrete which is sprayed onto the walls and ceiling of the mine to ensure structural integrity. Overall, both the DPM and inorganic levels in the mine particulate are of concern. Overall TSP and PM10 levels were not significant, as the mass of larger particles is kept low due to water sprays, gravitational settling and the humidity in the mine. 
Table 4: $\quad$ Inorganics found in PM10. Site 1-4 values are averages over the sampling period in $\mathrm{mg} / \mathrm{m}^{3}$.

\begin{tabular}{|c|c|c|c|c|c|}
\hline Element & $\begin{array}{c}\text { TWA } \\
\text { (NIOSH) }\end{array}$ & Site 1 & Site 2 & Site 3 & Site 4 \\
\hline $\begin{array}{l}\text { Magnesium } \\
\left(\mathrm{mg} / \mathrm{m}^{3}\right)\end{array}$ & $10 \mathrm{mg} / \mathrm{m}^{3}$ & 0.002 & 0.005 & 0.002 & 0.005 \\
\hline $\begin{array}{l}\text { Nickel } \\
\left(\mathrm{mg} / \mathrm{m}^{3}\right)\end{array}$ & $0.015 \mathrm{mg} / \mathrm{m}^{3}$ & 0.001 & 0.003 & 0.004 & 0.005 \\
\hline $\begin{array}{l}\text { Silica, } \\
\left(\mathrm{mg} / \mathrm{m}^{3}\right)\end{array}$ & $0.05 \mathrm{mg} / \mathrm{m}^{3}$ & 0.050 & 0.044 & 0.071 & 0.073 \\
\hline $\begin{array}{c}\text { Vanadium } \\
\text { dust }\left(\mathrm{mgV} / \mathrm{m}^{3}\right)\end{array}$ & $\begin{array}{c}0.05 \mathrm{mgV} / \mathrm{m}^{3} \\
(15 \mathrm{~min})\end{array}$ & 0.001 & 0.002 & 0.005 & 0.005 \\
\hline Iron $\left(\mathrm{mg} / \mathrm{m}^{3}\right)$ & $0.23 \mathrm{mg} / \mathrm{m}^{3}$ & 0.056 & 0.127 & 0.202 & 0.195 \\
\hline
\end{tabular}

In general, both the DustTrak and the SMPS showed a reasonably good agreement with each other and with the SMPS, generally within $10 \%$. However both the DustTrak and especially the SMPS showed elevated mass levels at sites 2 and 4, likely due to condensed water on the aerosol particles. This was not a problem for NanoMOUDI samples were weighed and analysed in a dry state.

Direct reading instruments such as the DustTrak should always be calibrated against a gravimetric standard. For the mine in question, it would be advisable to fit a diffusion dryer before the sample inlet, so as to remove excess moisture, allowing the dry particle mass to be measured. The work showed that a P-Trak is unsuitable for DPM measurement as DPM mass was often inversely proportional to number concentration.

As mentioned, the mine was operating at only $30 \%$ of its usual capacity while the measurements were performed. It could be expected that the DPM values could triple once production is scaled back up at the mine. However, the ventilation and air conditioning system (or at least the fans which supply the air) were reportedly operating at $100 \%$ capacity. Due to the humidity, temperature and DPM problems which were found, significant remedial action is required. 


\section{Conclusion}

This work provided a comprehensive evaluation of the DPM and PM levels in an underground mine, including the spatial and temporal information, as well as composition analysis.

Very high levels of DPM were found in the mine, which are likely to only increase once production levels are increased. There was however a slight disconnect between mine average DPM and worker exposure, as worker practices differ, and some workers spend most of their time in air conditioned cabs.

For the mine in question, optimisation of the ventilation system would be advisable, couples with engineering controls such as additional filtration or particulate removal/agglomeration technology. Further study into DPM levels in Australian mines and the formulation of binding exposure limits is warranted.

\section{References}

[1] Wichmann, H.E., Diesel Exhaust Particles. Inhalation Toxicology, 19(Suppl.1), pp. 241-244, 2007.

[2] Mühlfeld, C., Rothen-Rutishauser, B., Blank, F., Vanhecke, D., Ochs, M. \& Gehr, P., Interactions of Nanoparticles With Pulmonary Structures and Cellular Responses. American Journal of Physiology - Lung Cell Molecular Physiology, 294(5), pp. L817-L829, 2008.

[3] Diesel Exhaust: A Critical Analysis of Emissions, Exposures, and Health Effects. A Special Report of the Institute's Working Group; Health Effects Institute Web Site, pp. 294, 1995. pubs.healtheffects.org/view.php?id=1 1

[4] Pope, A., Burnett, R., Thun, M., Calle, E., Krewski, D., Ito, K. \& Thurston, G., Lung Cancer, Cardiopulmonary Mortality, and Long-Term Exposure to Fine Particulate Air Pollution. Journal of the American Medical Association, 287(9), pp. 1132-1141, 2002.

[5] Carcinogenic Effects of Exposure to Diesel Exhaust; National Institute of Occupational Safety and Health (NIOSH), Current Intelligence Bulletin 50, 1988, Cincinnati, Ohio, www.cdc.gov/niosh/88116_50.html

[6] Monographs on the Evaluation of Carcinogenic Risks to Humans Diesel and Gasoline Engine Exhausts and Some Nitroarenes; World Health Organisation, International Agency for Research on Cancer website, 46, p. 458, 1989, Lyon, France. monographs.iarc.fr/ENG/Monographs/vol46 /volume46.pdf

[7] Cantrell, B.K. \& Watts, W.F., Diesel Exhaust Aerosol: Review of Occupational Exposure. Applied Occupational and Environmental Hygiene, 12(12), pp 1019-1026, 1997.

[8] Cash, D. \& Baughman, W., DPM exposure in metal and nonmetal mines in the United States 2002-2005 and the 2005 Final Rule on the Interim Limit. Proceeding of Mining Diesel Emissions Conference (MDEC), Markham, Ontario, October 12-14, 2005. 
[9] Bugarski, Schnakenberg \& Patts, Implementation of Diesel Particulate Filter Technology in Underground Metal and Nonmetal Mines; National Institute for National Safety and Health, Centre for Disease Control Web Site, Pittsburgh, USA, www.cdc.gov/niosh/mining/pubs/pdfs/iodpf.pdf

[10] Mining Safety and Health Research at NIOSH: Reviews of Research Programs of the National Institute for Occupational Safety and Health. NISBN: 0-309-66636-8, National Academies Press: Washington DC, 2007.

[11] Biswas, P. \& Wu, C. Nanoparticles and the environment. Journal of the air \& waste management association, 55(6), pp. 708-746, 2005. 